\title{
Why do People Avoid Medical Care? A Qualitative Study Using National Data
}

\author{
Jennifer M. Taber, Ph.D., Bryan Leyva, B.A, and Alexander Persoskie, Ph.D.
}

National Cancer Institute, National Institutes of Health, Bethesda, MD, USA

BACKGROUND: Many studies have examined barriers to health care utilization, with the majority conducted in the context of specific populations and diseases. Less research has focused on why people avoid seeking medical care, even when they suspect they should go.

OBJECTIVE: The purpose of the study was to present a comprehensive description and conceptual categorization of reasons people avoid medical care.

DESIGN: Data were collected as part of the 2008 Health Information National Trends Survey, a cross-sectional national survey.

PARTICIPANTS: Participant-generated reasons for avoiding medical care were provided by 1,369 participants (40\% male; $M_{a g e}=48.9 ; 75.1 \%$ non-Hispanic white, 7.4\% non-Hispanic black, 8.5\% Hispanic or Latino/ a).

MAIN MEASURES: Participants first indicated their level of agreement with three specific reasons for avoiding medical care; these data are reported elsewhere. We report responses to a follow-up question in which participants identified other reasons they avoid seeking medical care. Reasons were coded using a general inductive approach.

KEY RESULTS: Three main categories of reasons for avoiding medical care were identified. First, over one-third of participants $(33.3 \%$ of 1,369$)$ reported unfavorable evaluations of seeking medical care, such as factors related to physicians, health care organizations, and affective concerns. Second, a subset of participants reported low perceived need to seek medical care (12.2\%), often because they expected their illness or symptoms to improve over time $(4.0 \%)$. Third, many participants reported traditional barriers to medical care (58.4\%), such as high cost $(24.1 \%)$, no health insurance $(8.3 \%)$, and time constraints (15.6\%). We developed a conceptual model of medical care avoidance based on these results. CONCLUSIONS: Reasons for avoiding medical care were nuanced and highly varied. Understanding why people do not make it through the clinic door is critical to extending the reach and effectiveness of patient care, and these data point to new directions for research and strategies to reduce avoidance.

KEYWORDS: Medical care avoidance; Health care barriers; Health care utilization; Qualitative.

Received May 23, 2014

Revised September 24, 2014

Accepted October 20, 2014

Published online November 12, 2014
J Gen Intern Med 30(3):290-7

DOI: $10.1007 / \mathrm{s} 11606-014-3089-1$

(c) Society of General Internal Medicine 2014

\section{INTRODUCTION}

People often avoid seeking medical care even when they suspect it may be necessary; ${ }^{1-4}$ nearly one-third of respondents in a recent national United States (U.S.) survey reported avoiding the doctor. ${ }^{5-7}$ Even individuals with major health problems ${ }^{4,8,9}$ or who are experiencing symptoms ${ }^{10-12}$ avoid seeking medical care. For example, in one study, $17 \%$ of patients diagnosed with rectal tumors reported that they waited a year or more to seek medical consultation after noticing symptoms, with some waiting up to five years. ${ }^{12}$ Avoiding medical care may result in late detection of disease, reduced survival, and potentially preventable human suffering. ${ }^{1,8,13,14}$

In the present study, we sought to understand why people avoid seeking medical care. Avoidance of medical care has been defined as "keeping away from something [in a medical context] that is thought to cause mental or physical distress." Avoidance can also occur as a result of barriers, which can be defined as factors that limit access to or ease of obtaining quality health care (e.g., financial concerns, time constraints). ${ }^{1,15}$ Avoidance of medical care can occur at any point on the disease continuum, including preventing and detecting asymptomatic disease, noticing symptoms and interpreting their significance, seeking care after determining a potential need, and complying with recommended treatment. ${ }^{1,2,16}$ Of note, the term "patient delay" has also been used to describe phenomena related to avoidance, but guidelines for research on early cancer diagnosis have suggested instead using the more informative terms "appraisal interval" (the time taken to interpret symptoms) and "help-seeking interval" (the time taken to seek care after determining a need). ${ }^{17}$

To date, research on avoidance of medical care has been limited in the extent to which it examines the broad spectrum of reasons for avoidance (but see ${ }^{7}$ ), often focusing on specific factors such as barriers or psychological characteristics (e.g., lack of insurance, fear of a diagnosis). ${ }^{4-6,15,18-24}$ A conceptual review of reasons people avoid medical care identified only six qualitative or mixed-methods studies assessing participantgenerated reasons, all of which used convenience samples with predominately white participants. ${ }^{1}$ Moreover, five of the six studies reviewed assessed avoidance of specific 
procedures. ${ }^{1}$ The exception was a focus group study among a sample of Hispanics that explored reasons for avoiding medical visits in response to warning signs of heart disease, cancer, and diabetes. ${ }^{11}$ This qualitative study identified factors such as low trust in doctors, low perceived severity of symptoms, emotional factors (e.g., denial, avoiding worry, embarrassment), practical barriers, and prior negative experiences as contributing to avoidance. ${ }^{11}$

Given the significance and prevalence of medical care avoidance in the U.S., ${ }^{1,5}$ there is a need for continued basic qualitative research that can uncover the reasons underlying this phenomenon. Simply put, why do people avoid medical visits that could save lives or reduce suffering, whether through early detection of disease or timely treatment? To help answer this question, the present study used data collected from a large national sample. The purpose of the study was to identify the reasons people avoid seeking medical care and to classify these reasons into conceptually distinct categories reflecting underlying factors contributing to avoidance. Ultimately, we sought to develop a model of medical care avoidance that can inform efforts to promote care-seeking, help providers reduce avoidance in their patient populations, and promote theoretical advancement in this area of research.

\section{METHODS}

\section{Data Source}

Data were obtained from the National Cancer Institute's 2008 Health Information National Trends Survey (HINTS). This cross-sectional survey collects data from a nationally representative sample of civilian non-institutionalized adults aged 18 and over in order to assess trends and patterns in health communication. Data were collected from January through April 2008. Phone and mail surveys were administered to maximize response rates (24.2 and $31.0 \%$, respectively). The survey was completed by 7,674 participants. Details of the study design have been published elsewhere. ${ }^{25-27}$

\section{Measures}

Participants were first asked whether they "avoid visiting their doctor even when they suspect they should." Participants who responded "yes" $(n=2,327)$ were then asked to what extent they endorsed three researcher-identified reasons for avoiding the doctor (i.e., feeling uncomfortable when their body is being examined, fear of having a serious illness, and because it makes them think of dying); results concerning these items have been published elsewhere. ${ }^{5,7,18,24}$ Next, participants were asked whether there were "any other reasons why you avoid seeing your doctor," and either wrote their response in a small box if completing a mail survey or stated their response to an interviewer, who summarized their response, if completing a phone survey. Responses were brief and typically consisted of a short phrase or sentence. Interpretable responses were provided by
1,369 participants (58.8\% of those who reported avoidance in response to the initial question). Eight participants provided uninterpretable responses either because they failed to provide a reason (e.g., "don't know") or because it was impossible to determine the motivation (e.g., "ambivalence" or "family tradition"), with 164 participants listing more than one reason.

\section{Data Management and Analytic Approach}

An independent research company was contracted to preliminarily clean the participant-generated responses ( $n=1,377$; see 7 for a report of these uncoded responses) by using short phrases to standardize responses (e.g., "Busy" and "I'm too busy to go to the doctor" were recoded into "Too busy"). A prior study reported the top five of these uncoded responses (i.e., preference for selfcare or alternative care, dislike or distrust doctors, fear or dislike of medical treatments, time, and money) and predictors of these responses. ${ }^{7}$ For the present study, the three study authors analyzed these short phrases provided by the research company in conjunction with participants' raw responses using a general inductive data analysis approach, a method in which a theory or conceptual model is developed through an iterative process of coding, grouping codes into categories based on underlying concepts, and forming a model or generating hypotheses based on the data. ${ }^{28,29}$ Coding was conducted by discussion of each participant response among all three authors; in rare cases when two authors disagreed, the third author acted as arbiter. Through this process, the authors identified emergent codes and collapsed and reconceptualized existing codes as necessary. After assigning codes, all authors participated in an iterative process of placing codes into sub- and superordinate categories. The goal of the coding and categorization was to identify conceptually distinct factors underlying reasons for avoiding medical care, and to organize these factors into a conceptual framework that could provide targets for intervention and stimulate further research on avoidance. Upon completing the coding and categorizing, we reviewed existing theory on care-seeking and avoidance to determine whether our data provided support for a pre-existing theory or whether we should develop a new theory and/or model. We provide quantitative counts of the number of respondents, listing each reason in order to convey the frequency of responses, and qualitatively describe themes to provide context and explanation.

\section{RESULTS}

Among participants who indicated avoiding medical care, characteristics of those who provided qualitative responses $(n=1,369)$ compared to those who did not $(n=958)$ are shown in Table 1. Participants who provided responses were more likely to be white, female, younger, married, born in the U.S., to have completed the survey by phone, and to have higher income and education, but were less likely to have health insurance. Of the 1,369 participants who provided interpretable "other" responses, fewer than half $(43.5 \%, n=595)$ endorsed at least one researcher-identified reason (answered 
Table 1 Characteristics of Participants Who Reported Avoiding the Doctor and Either Did or Did Not Provide an Interpretable Qualitative "Other" Reason for Avoidance

\begin{tabular}{|c|c|c|c|}
\hline & \multicolumn{2}{|c|}{ Provided qualitative "other" reason } & \multirow[t]{3}{*}{$\chi 2$ value, $p$ value } \\
\hline & \multirow{2}{*}{$\frac{\text { Yes }(n=1,369)}{n(\%)}$} & \multirow{2}{*}{$\frac{\text { No }(n=958)}{n(\%)}$} & \\
\hline & & & \\
\hline Age & $48.9(14.9)^{*}$ & $52.7(17.8)^{*}$ & $t(2301)=5.63, p<0.001^{\dagger}$ \\
\hline \multicolumn{3}{|l|}{ Gender } & \multirow{3}{*}{$\chi 2(1)=5.49, p=0.02$} \\
\hline Male & $547(40.0)$ & $429(45.8)$ & \\
\hline Female & $822(60.0)$ & $528(55.1)$ & \\
\hline \multicolumn{3}{|l|}{ Marital status } & \multirow[t]{3}{*}{$\chi^{2}(1)=4.95, p=0.03$} \\
\hline Married or living as married & $781(57.1)$ & $496(44.8)$ & \\
\hline Not married & $555(40.5)$ & $427(44.6)$ & \\
\hline \multicolumn{3}{|l|}{ Education } & \multirow[t]{5}{*}{$\chi^{2}(3)=96.84, p<0.001$} \\
\hline Less than high school & $115(8.4)$ & $165(8.3)$ & \\
\hline High school graduate & $302(22.1)$ & $299(31.2)$ & \\
\hline Some college & $442(32.3)$ & $254(26.5)$ & \\
\hline College graduate & $478(34.9)$ & $204(21.3)$ & \\
\hline \multicolumn{3}{|l|}{ Household income } & \multirow[t]{7}{*}{$\chi^{2(5)}=37.41, p<0.001$} \\
\hline$\$ 0$ to $\$ 9,999$ & $76(5.6)$ & $75(7.8)$ & \\
\hline$\$ 10,000$ to $\$ 19,999$ & $139(10.2)$ & $135(14.1)$ & \\
\hline$\$ 20,000$ to $\$ 49,999$ & $362(26.4)$ & $284(29.7)$ & \\
\hline$\$ 50,000$ to $\$ 74,999$ & $242(17.7)$ & $132(13.8)$ & \\
\hline$\$ 75,000$ to $\$ 99,999$ & $154(11.3)$ & $85(8.9)$ & \\
\hline$\$ 100,000$ or more & $224(16.4)$ & $98(10.2)$ & \\
\hline \multicolumn{3}{|l|}{ Race/ethnicity } & \multirow{8}{*}{$\chi^{2}(6)=40.56, p<0.001$} \\
\hline Hispanic or Latino & $116(8.5)$ & $115(12.0)$ & \\
\hline White & $1028(75.1)$ & $597(62.3)$ & \\
\hline Black or African American & $101(7.4)$ & $113(11.8)$ & \\
\hline American Indian or Alaska Native & $12(0.9)$ & $12(1.3)$ & \\
\hline Asian & $28(2.0)$ & $34(3.6)$ & \\
\hline Native Hawaiian or other Pacific lslander & $3(0.2)$ & $5(0.5)$ & \\
\hline Biracial & $27(2.0)$ & $26(2.7)$ & \\
\hline \multicolumn{3}{|l|}{ Nativity } & \multirow[t]{3}{*}{$\chi^{2}(1)=8.53, p=0.003$} \\
\hline Born in the United States & $1206(88.1)$ & $795(83.0)$ & \\
\hline Not born in the United States & $131(9.6)$ & $127(13.3)$ & \\
\hline \multicolumn{3}{|l|}{ Health insurance status } & \multirow[t]{3}{*}{$\chi^{2}(1)=15.72, p<0.001$} \\
\hline Yes & $1073(78.4)$ & $805(84.0)$ & \\
\hline No & $281(20.5)$ & $134(14.0)$ & \\
\hline \multicolumn{3}{|l|}{ Personal history of cancer } & \multirow{3}{*}{$\chi^{2}(1)=4.77, p=0.03$} \\
\hline Yes & $114(8.3)$ & $104(10.9)$ & \\
\hline No & $1227(89.6)$ & $820(85.6)$ & \\
\hline \multicolumn{3}{|l|}{ Survey response mode } & \multirow{3}{*}{$\chi^{2}(1)=38.92, p<0.001$} \\
\hline Mail & $642(46.9)$ & $575(60.0)$ & \\
\hline Telephone & $727(53.1)$ & $383(40.0)$ & \\
\hline
\end{tabular}

Note: Percentages do not sum to 100 because of missing data

*Variable is continuous and values indicate mean (standard deviation)

* Test of comparison is $t$ test

"agree/strongly agree" versus "disagree/strongly disagree") for avoiding medical care. Approximately one-fourth reported avoiding medical care because of feeling uncomfortable $(26.8 \%, n=369)$ or fearing a serious illness $(26.4 \%, n=363)$, with substantially fewer reporting avoiding medical care because it made them think of dying $(8.2 \%, n=113)$.

From the analysis of participant-generated qualitative reasons for avoiding the doctor, we identified three overarching, conceptually distinct categories of reasons for avoiding medical care based on whether participants perceived seeking medical care to be necessary, available to them as a course of action, and favorable or beneficial. In the first category, "low perceived need to seek medical care," responses indicated a determination that seeking medical care was unnecessary. In the second category, "traditional barriers to medical care," responses indicated that seeking medical care was not an option because of a lack of resources. In the third category, "unfavorable evaluations of seeking medical care," people evaluated some aspect of the care-seeking process as negative. A fourth category, labeled "personality traits," was also identified as a reason for avoidance that did not fall into any of the three major categories. Each category and relevant subcategories are described in detail below and outlined in Fig. 1.

\section{Low Perceived Need to Seek Medical Care}

Many responses, coded as "low perceived need," indicated the belief that seeking medical care was unnecessary $(n=167)$. The most common reasons were that medical problems would either "improve over time" or "improve on their own" ( $n=55$; e.g., "Whatever the symptoms, time will make it better"; "I believe the body will heal itself in most cases"). Participants often indicated that this was contingent on the problem not being very serious (e.g., "What I have will pass. I only go if I think it is serious"), with many stating not being "sick enough" as a reason for avoiding medical care $(n=40$; 


\begin{tabular}{|c|c|c|c|}
\hline 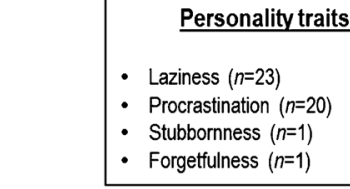 & & $\begin{array}{l}\text { Unfavorable evaluation } \\
\text { Physician factors, } n=178 \\
\text { - Interpersonal factors }(n=98)\end{array}$ & $\begin{array}{l}\text { Affective concerns, } n=76 \\
\text { - Fear of bad news }(n=31) \\
\text { - Fer }\end{array}$ \\
\hline 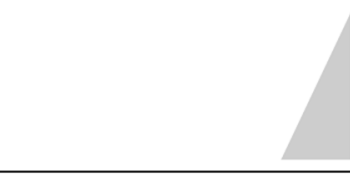 & $\begin{array}{l}\frac{\frac{\text { Traditional barriers }}{\text { to medical care, }}}{\underline{n=800}} \\
\text { - Cost is too high }(n=330) \\
\text { - Not enough time/too busy }(n=214)\end{array}$ & $\begin{array}{l}\text { - Bere about patients }(n=8) \\
\text { Believes doctors are } \\
\text { too busy }(n=8) \\
\text { - Poor relationship with } \\
\text { doctor }(n=2) \\
\text { - Perceives discrimination }(n=1)\end{array}$ & $\begin{array}{l}\text { - Embarrassment }(n=15) \\
\text { - Feels guilty about unhealthy } \\
\text { behavior }(n=2) \\
\text { Expected negative outcomes, } n=\mathbf{4 2} \\
\text { - Dislikes or is avoiding }\end{array}$ \\
\hline $\begin{array}{l}\frac{\text { Low perceived need to }}{\text { seek medical care, }} \\
\text { - } \\
\text { Believes illness will improve with } \\
\text { time/on its own }(n=55) \\
\text { - Not sick enough ( } n=40) \\
\text { - Does not have } \\
\text { health problems }(n=40) \\
\text { - Tries to take care of self ( } n=13) \\
\text { - Works for or is medical professional } \\
\text { - Cons) } \\
\text { - Pre a hypochondriac }(n=5) \\
\text { - Prefers spiritual healing }(n=3) \\
\text { - Prefers natural remedies }(n=2) \\
\text { Family provides care }(n=1)\end{array}$ & $\begin{array}{l}\text { - Lack of health insurance ( } n=113) \\
\text { - Inconvenient clinic hours } \\
\text { (i.e., during work; } n=57) \\
\text { - Co-pay is too high ( } n=35) \\
\text { - Inadequate health } \\
\text { insurance ( } n=29) \\
\text { - Transportation difficulties }(n=18) \\
\text { - Does not have a doctor }(n=13) \\
\text { - Health insurance, } \\
\text { unspecified ( }(n=9) \\
\text { - Distance is too far }(n=7) \\
\text { - Too sick to travel to } \\
\text { doctors' office }(n=6) \\
\text { - Physical or mental condition prevents } \\
\text { from going }(n=5) \\
\text { - Doctor is inaccessible }(n=5) \\
\text { - Lack of childcare }(n=3) \\
\text { - Language barriers }(n=2)\end{array}$ & $\begin{array}{l}\text { - Medical factors ( } n=81 \text { ) } \\
\text { - Low confidence in } \\
\text { doctors' expertise ( } n=61) \\
\text { - Believes doctor will do } \\
\text { unnecessary tests or prescribe } \\
\text { unnecessary medication ( } n=13 \text { ) } \\
\text { - Believes doctors care more about } \\
\text { money than patients ( } n=9 \text { ) } \\
\text { - Believes does not get the care } \\
\text { needed, unspecified ( }(n=5) \\
\text { Organizational factors, } n=108 \\
\text { - Long waiting times ( } n=52) \\
\text { - Hassle ( } n=51) \\
\text { - Avoiding sick people }(n=6) \\
\text { - Dislikes HMOs }(n=1) \\
\text { - Dislikes smells }(n=1) \\
\text { - Lack of continuity }(n=1)\end{array}$ & $\begin{array}{l}\text { medical recommendations ( } n=19) \\
\text { - Cannot take or } \\
\text { dislikes medication ( } n=12) \\
\text { - Knows will not follow } \\
\text { recommendations ( } n=7) \\
\text { - Believes will leave } \\
\text { feeling worse }(n=2) \\
\text { - Does not want to be hospitalized ( } n=2) \\
\\
\text { Other reasons, } n=67 \\
\text { - Dislikes going, unspecified ( } n=46) \\
\text { - Has had specific negative experiences } \\
\text { at the doctors' in the past }(n=11) \\
\text { - Denial (not explained further; } n=4) \\
\text { - Not a priority ( } n=3) \\
\text { - Has an untreatable illness ( } n=2) \\
\text { - Does not want doctor to know about } \\
\text { other treatments }(n=1) \\
\text { - Does not want symptoms or health } \\
\text { problem documented }(n=1)\end{array}$ \\
\hline
\end{tabular}

Note: N's for overarching categories represent the number of unique respondents who gave a response in that category. Because some participants gave multiple reasons in one category, the number of responses given for specific reasons may total more than the overall number of responses for a particular category.

Figure 1 Participant-generated reasons for avoiding medical care $(n=1,369)$.

e.g., "Don't go unless there is a real need"). Despite the question stem referring to avoiding the doctor "when you think you should go," many participants said they avoided medical care because they did not have health problems ( $n=40$; e.g., "Not sick. If not broken don't fix"). A small subset of participants also reported avoiding medical care because they "try to take care of themselves" ( $n=13$; e.g., by using over-the-counter medication), were either a doctor or worked in a health care setting $(n=9)$, were afraid to be labeled a hypochondriac $(n=5)$, or preferred to rely on spiritual healing $(n=3)$ or to use natural remedies $(n=2)$.

\section{Traditional Barriers to Medical Care}

The largest overarching category of reasons for avoidance of medical care may be best described as "traditional barriers to medical care" ( $n=800,58.4 \%)$. In this category, we included responses indicating circumstances or obstacles limiting access to medical care. Participants reported having too little time or being too busy to seek medical care $(n=214)$, that clinic hours were inconvenient ( $n=57$; e.g., "Have to take time off from work"), that transportation was difficult $(n=18)$ or the distance was too far $(n=7)$, that they were too sick to travel to the doctor's office $(n=6)$, or that an existing physical $(n=5$; e.g., multiple sclerosis) or mental health (e.g., depression, severe anxiety) problem prevented them from going. Financial reasons included concerns about overall cost $(n=330)$, co-pays $(n=35)$, and health insurance $(n=151)$. Few reported not having a doctor $(n=13)$, that their doctor was inaccessible $(n=5$; e.g. "I don't see him, I just see nurses, he is never there"), not having childcare $(n=3)$, or language barriers $(n=2)$.

\section{Unfavorable Evaluations of Seeking Medical Care}

Approximately one-third of participants $(n=456,33.3 \%)$ provided responses that demonstrated unfavorable evaluations of the process or outcomes of seeking medical care.

Physician Factors. The most frequently reported reasons for unfavorable evaluations were factors related to physicians $(n=178)$. There were two major categories of physician factors: interpersonal concerns $(n=98)$ and concerns about the quality of medical care $(n=81)$. The most frequent interpersonal concerns involved communication concerns $(n=34)$, including perceptions that doctors do not follow-up, that communication is difficult, disliking how doctors communicate (e.g., "Doctors often make you feel like you're stupid"), disliking the manner in which doctors provide advice or recommendations (e.g., "Tired of being chewed out for not following medical advice"), perceiving that doctors do not listen to patients (e.g., "They are impersonal-paying more attention to computers"; "My experience is one of not being heard/considered"), and perceiving that doctors do not take patients' concerns seriously. Other interpersonal reasons 
included general mistrust of doctors (e.g. "I just don't trust them"; $n=25$ ), believing that doctors do not care about patients (e.g., "I don't always feel that they truly care"; $n=8$ ), and perceiving that doctors are too busy $(n=8)$. Participants also reported a broad dislike of doctors, without elaboration $(n=21)$.

The most frequent reason concerning the quality of medical care was that participants had low confidence in doctors' expertise $(n=61)$, which included beliefs that doctors would not be able to diagnose patients (e.g., "Fear that they won't know what's wrong either"), that doctors would provide incorrect diagnoses (e.g., "They usually make the wrong diagnosis"), and that doctors simply "make things worse." This category also included more general statements about a lack of confidence in medical providers (e.g., "No confidence in today's medical field"). Participants also expressed concerns that doctors would prescribe unnecessary tests or medication $(n=13)$, and several participants stated that "doctors care more about money than patients" $(n=9)$.

Organizational Factors. Many reasons for unfavorable evaluations concerned aspects of the medical system $(n=108)$, such as long waiting times $(n=52)$ and "hassle" $(n=51)$, which included the hassle of making timely appointments (e.g., "Usually can't see doctor at the time of a problem") or even making appointments at all (e.g., "Difficult to get appointment, office too busy"), as well as general hassle (e.g., "It's a big bother"). Several participants reported not wanting to be around sick people $(n=6)$. Additional reasons are shown in Fig. 1.
Affective Concerns. Some participants reported that anticipated fear, embarrassment, or guilt kept them from seeking medical care $(n=76)$. Responses concerning fear included the fear of receiving bad news $(n=31)$ such as a medical diagnosis or a prognosis concerning an already diagnosed condition (e.g., "Afraid they might say my diabetes is worse"). Participants also reported fear of needles $(n=7)$, pain $(n=5)$, and specific procedures such as surgery or prostate exams $(n=5)$, or simply reported "fear" $(n=12)$. Relatedly, participants reported the specific emotion of embarrassment $(n=15)$, including embarrassment about weight $(n=4)$, health issues $(n=2)$, or general feelings of discomfort $(n=9)$. Finally, some participants reported feeling guilty about potentially disclosing engagement in unhealthy behavior $(n=2)$.

Expected Negative Outcomes. Some responses pertained to beliefs that the outcome of seeking medical care would be negative, including dislike of a provider's medical recommendations or the perception that recommendations would not be useful $(n=42)$. These responses included avoidance of specific recommendations to change behavior $(n=19)$; participants often disliked the emphasis on weight loss ( $n=10$; e.g., "Hearing the same old-lose weight" and "Always have to hear about how fat I am") or other health problems such as alcohol consumption, smoking, or high blood pressure. Some participants indicated they disliked or could not take medication ( $n=12$; e.g., "I hate Rx drugs- the side effects scare me") or that they would not follow a physician's recommendations $(n=7)$. Additional responses are reported in Fig. 1.

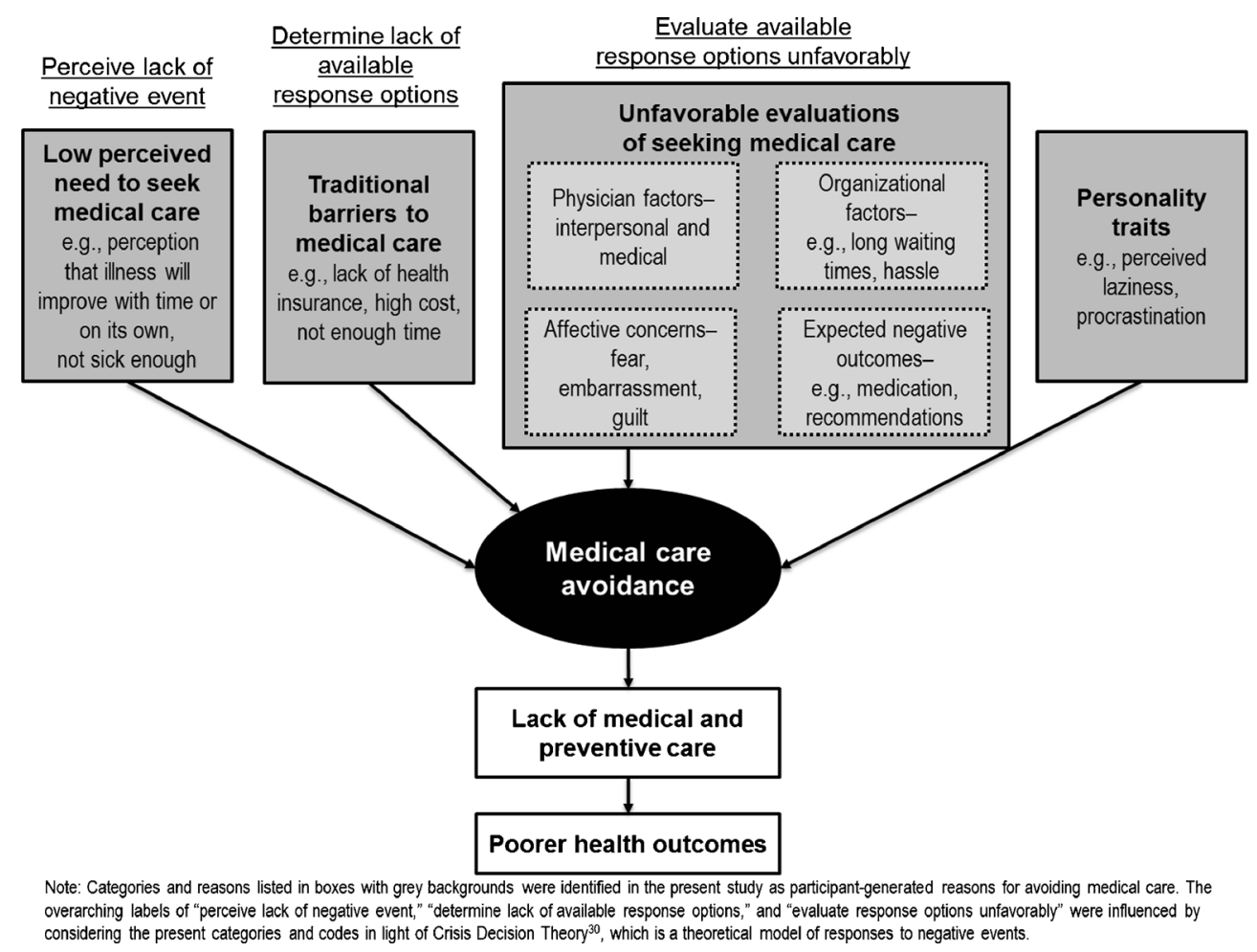

Figure 2 Conceptual model of medical care avoidance. 
Other Reasons. Several additional reasons were reported that were either nonspecific or did not fall into another category ( $n=67)$. The majority of these responses included generally not liking or wanting to go to the doctor $(n=46)$. Participants also reported having had past negative experiences but not specifying the nature of these experiences $(n=11)$, denial $(n=4)$, and not viewing seeking medical care as a priority $(n=3)$. Fig. 1 presents other reasons reported by few participants.

\section{Self-Ascribed Personality Traits}

A fourth category of reasons for avoiding medical care concerned personality traits $(n=45)$. Specifically, participants responded that they were "lazy" $(n=23)$ or that they "procrastinate" ( $n=20)$, with little elaboration. Two additional responses are shown in Fig. 1.

\section{Conceptual Model of Medical Care Avoidance}

Fig. 2 presents the conceptual model of medical care avoidance that emerged from our categorization of participant-generated reasons. The language used to describe this model, as well as the conceptualization of avoidance at different stages of the careseeking process, was influenced by Crisis Decision Theory, which describes how people respond to negative events more generally. ${ }^{30}$ Our conceptual model proposes that avoidance may begin prior to noticing a need (e.g., avoidance of early detection or preventive services) or in the process of evaluating symptoms, or that avoidance can occur after a need is identified if people perceive a lack of resources, evaluate medical care unfavorably, or have a personality trait that discourages care-seeking. The model also proposes that avoiding medical care for any of these reasons would lead to a lack of medical and preventive care and, ultimately, poorer health outcomes. A specific comparison of our model of medical care avoidance to the more general Crisis Decision Theory ${ }^{30}$ is presented in the Discussion.

\section{DISCUSSION}

This study presents the first comprehensive qualitative analysis of reasons for avoiding medical care among the general U.S. public. Using a diverse nationally representative sample and participant-generated responses, we applied inductive qualitative research methods to identify and categorize reasons for and to develop a conceptual model of medical care avoidance. Three overarching categories of reasons emerged based on the necessity, availability, and desirability of care-seeking: 1) low perceived need to seek medical care; 2) traditional barriers to medical care, in which people may want to seek care but are limited in their ability to do so; and 3) unfavorable evaluations of seeking medical care, in which people may perceive care- seeking as necessary and an available option, but not desirable. Notably, unlike much of the prior research, the reasons identified here are applicable across a broad range of clinical settings and are particularly relevant for primary care. Primary care settings are patients' first point of contact for most health issues, and increasingly function as the hub of all medical care. ${ }^{31}$ Understanding why people fail to make it through the clinic door is critical to extending the reach and effectiveness of patient care.

Many of the reasons identified here are consistent with factors previously described in prior research, including studies of smaller patient and community samples, and reflected in theories of health behavior and health care use. ${ }^{1-4,7,10,11,32-37}$ Interestingly, the categories of reasons that emerged from the present study mapped almost directly onto a general psychological model of responses to negative events - Crisis Decision Theory ${ }^{30}$ — which has not previously been used as a framework for understanding medical care avoidance. Crisis Decision Theory posits that people respond to negative events first by appraising the severity of threat, next by identifying available response options, and lastly by evaluating available response options. ${ }^{30}$ Putting our results into the language of this framework, participants who reported low perceived need to seek medical care may have appraised little threat or perceived high control to respond to the "crisis" themselves. Participants who reported factors limiting access may have felt that their response options were limited and that seeking medical care was not an option. Participants who reported unfavorable evaluations of medical care may have moved beyond both of these stages - they may have recognized a need to seek care (sufficient threat) and perceived seeking care to be a feasible option, but - in the language of Crisis Decision Theory - did not expect the gains of seeking care to outweigh the costs.

Our conceptual model proposes that perceptions of the necessity, availability, and desirability of seeking medical care may be prime intervention targets for reducing medical care avoidance. Although in some cases participants may have correctly assessed that their symptoms would go away with time or heal on their own, low perceived need to seek care suggests a need to educate patients on how to recognize symptoms for common health problems and the value of medical screening for asymptomatic conditions. For example, many people falsely believe they can tell when their blood pressure is high. ${ }^{38}$ Education about the importance of seeking preventive health care and regular checkups is critical. Public health efforts might include telephone or printed client reminders that medical visits are vital to health maintenance, that regular checkups can identify risk factors and problems before they become serious, and that treatments are often more effective when disease is caught early. ${ }^{39}$ Interventions utilizing technology such as telemedicine and eHealth (e.g., patient portals) may increase patient engagement with health care, provided they facilitate awareness of health care services and disease management. ${ }^{40,41}$ In terms of symptom appraisal, research should assess whether people must reach certain thresholds prior to seeking care.

Traditional barriers limiting access to or ease of seeking medical care, such as lack of health insurance and time 
constraints, were the most commonly cited reasons for avoiding medical care, consistent with prior research. ${ }^{7,21,22,42-44}$ With the advent of the Affordable Care Act (ACA), lack of health insurance may become less of a barrier, but our results indicate that inadequate health insurance and high co-pays are also reasons for avoiding medical care, as well as numerous other reasons that may not be abated by the ACA. Interventions targeting these barriers are an important area for continued research. Strategies designed to tackle multiple barriers simultaneously (e.g., case management, financial incentives such as costreduction strategies or efforts to limit out-of-pocket costs) and comprehensive approaches addressing multiple patient needs (e.g., multidisciplinary team care ${ }^{45}$ ) may be more effective in reducing avoidance than strategies that target only one barrier.

Finally, many people reported unfavorable evaluations of seeking medical care (e.g., communication problems, concerns about physicians' trustworthiness and expertise), consistent with prior research showing the impact of the patient-physician relationship and medical trust on medication adherence, health care utilization, and health outcomes. ${ }^{7,32,46-50}$ Much intervention research is focused on improving patient experiences and communication, ${ }^{51-55}$ and the frequency of responses indicating dislike of both physicians and the health care system confirms that this intervention focus is well-deserved. However, we also observed a variety of other reasons, such as avoiding specific recommendations or procedures, which could also be addressed through interventions aimed at changing negative perceptions about specific aspects of medical care.

\section{Limitations and Future Directions}

There are several important limitations of the present study. Medical care avoidance due to discomfort with physical examinations, fear of having a serious illness, and associating doctors with death may have been underestimated because these factors were assessed with closed-ended questions immediately prior to the open-ended question analyzed here. The pattern of differences in demographic factors among individuals who did and did not provide written reasons for avoiding seeking medical care suggest that responses were provided more often by people who may have been more favorably disposed to participate in research (e.g., those with higher incomes and education levels). Given the subjective nature of qualitative coding, alternate categorizations of the data are possible. In particular, reasons categorized here as "unfavorable evaluations of seeking medical care" have been conceptualized elsewhere as "cognitive barriers." 15 Few participants self-identified as members of racial and ethnic minority groups or were born outside the U.S., which is important because the breadth and distribution of reasons for medical care avoidance may be different among these populations. For example, although language is a strong barrier for many immigrant populations, ${ }^{56}$ only two participants identified language as a reason for avoiding care. Therefore, care should be taken to study reasons for avoidance among these specific populations.
Further, we cannot be certain that all respondents understood or paid attention to the exact item wording. We interpreted responses concerning "no health problems" as evidence for avoiding preventive screening or routine checkups. However, this is an extrapolation, and participants' intentions cannot be known.

In addition to informing intervention development, the present results are intended to generate hypotheses for future research. Participants tended to list only one response and were not encouraged to report all reasons that were important to them. If some people avoid medical care for multiple reasons, this may have reduced the overall reported prevalence of many reasons. Research is also necessary to test whether there is a linear decision-making strategy as suggested by Crisis Decision Theory, as it is possible that various reasons may interact and co-occur. For example, traditional barriers may exert more influence, or symptoms may be interpreted as less severe, when people negatively evaluate some aspect of care-seeking, (e.g., fearing bad news). Prospective research in which participants report symptoms and behavioral responses as they unfold would provide valuable insight into the process of decision-making surrounding avoidance. Researchers can also follow up on specific reasons that have been understudied and develop validated scales of reasons for medical care avoidance, and future research should test the predictive validity of these reasons for actual avoidance. Quantitative analyses are necessary because people cannot always accurately report their motivations ${ }^{57}$ and might not be fully aware of the specific reasons they avoid seeking medical care. The frequency of specific reasons reported here might overestimate or underestimate the impact of these reasons on actual avoidance. Finally, asking people to explain why they choose to seek medical care in some instances but not in others might provide better understanding of the potentially nuanced and dynamic patterns and processes of decision-making. ${ }^{2}$

Conflict of Interest: The authors declare that they do not have a conflict of interest.

Corresponding Author: Jennifer M. Taber, Ph.D.; National Cancer InstituteNational Institutes of Health, 9609 Medical Center Drive, Bethesda, MD 20892-9761, USA (e-mail: Jennifer.taber@nih.gov).

\section{REFERENCES}

1. Byrne SK. Healthcare avoidance: a critical review. Holist Nurs Pract. 2008;22:280-92.

2. Scott S, Walter F. Studying help-seeking for symptoms: The challenges of methods and models. Soc Personal Psychol Compass. 2010;4:531-47.

3. Yousaf O, Grunfeld EA, Hunter MS. A systematic review of the factors associated with delays in medical and psychological help-seeking among men. Health Psychol Rev. 2013:1-13

4. Smith LK, Pope C, Botha JL. Patients' help-seeking experiences and delay in cancer presentation: a qualitative synthesis. Lancet. 2005;366:825-31.

5. Vanderpool RC, Huang B. Cancer risk perceptions, beliefs, and physician avoidance in Appalachia: results from the 2008 HINTS Survey. J Health Commun. 2010;15(Suppl 3):78-91. 
6. Persoskie A, Ferrer RA, Klein WM. Association of cancer worry and perceived risk with doctor avoidance: an analysis of information avoidance in a nationally representative US sample. J Behav Med. 2014;37:977-87.

7. Kannan VD, Veazie PJ. Predictors of avoiding medical care and reasons for avoidance behavior. Med Care. 2014;52:336-45.

8. Lund-Nielsen B, Midtgaard J, Rorth M, Gottrup F, Adamsen L. An avalanche of ignoring-a qualitative study of health care avoidance in women with malignant breast cancer wounds. Cancer Nurs. 2011;34:277-85.

9. Kiefe CI, Funkhouser E, Fouad MN, May DS. Chronic disease as a barrier to breast and cervical cancer screening. J Gen Intern Med. 1998; 13:357-65.

10. Barbour JB, Rintamaki LS, Ramsey JA, Brashers DE. Avoiding health information. J Health Commun. 2012;17:212-29.

11. Larkey LK, Hecht ML, Miller K, Alatorre C. Hispanic cultural norms for health-seeking behaviors in the face of symptoms. Health Educ Behav. 2001;28:65-80.

12. Ristvedt SL, Trinkaus KM. Psychological factors related to delay in consultation for cancer symptoms. Psychooncology. 2005;14:339-50.

13. Richards MA, Westcombe AM, Love SB, Littlejohns P, Ramirez AJ. Influence of delay on survival in patients with breast cancer: a systematic review. Lancet. 1999;353:1119-26.

14. Ohl M, Tate J, Duggal M, et al. Rural residence is associated with delayed care entry and increased mortality among veterans with human immunodeficiency virus infection. Med Care. 2010;48:1064-70.

15. Carrillo JE, Carrillo VA, Perez HR, Salas-Lopez D, Natale-Pereira A, Byron AT. Defining and targeting health care access barriers. J Health Care Poor Underserved. 2011;22:562-75.

16. Reynolds LM, Consedine NS, Pizarro DA, Bissett IP. Disgust and behavioral avoidance in colorectal cancer screening and treatment: a systematic review and research agenda. Cancer Nurs. 2013;36:122-30.

17. Weller D, Vedsted $\mathbf{P}$, Rubin G, et al. The Aarhus statement: improving design and reporting of studies on early cancer diagnosis. $\mathrm{Br} \mathrm{J}$ Cancer 2012;106:1262-7.

18. Moser RP, Arndt J, Han PK, Waters EA, Amsellem M, Hesse BW. Perceptions of cancer as a death sentence: prevalence and consequences. J Health Psychol. Jul 172013.

19. Capp R, Rooks S, Wiler J, Zane R, Ginde A. National study of health insurance type and reasons for emergency department use. J Gen Intern Med. 2014;29:621-7.

20. Cheung PT, Wiler JL, Lowe RA, Ginde AA. National study of barriers to timely primary care and emergency department utilization among medicaid beneficiaries. Ann Emerg Med. 2012;60:4-10.e12.

21. Baker DW, Shapiro MF, Schur CL. Health insurance and access to care for symptomatic conditions. Arch Intern Med. 2000;160:1269-74.

22. DeVoe JE, Fryer GE, Phillips R, Green L. Receipt of preventive care among adults: insurance status and usual source of care. Am J Public Health. 2003;93:786-91

23. Goins RT, Williams KA, Carter MW, Spencer M, Solovieva T. Perceived barriers to health care access among rural older adults: a qualitative study. J Rural Health. 2005;21:206-13.

24. Ye J, Shim R, Rust G. Health care avoidance among people with serious psychological distress: analyses of 2007 Health Information National Trends Survey. J Health Care Poor Underserved. 2012;23:1620-9.

25. Cantor D, Coa K, Crystal-Mansour S, Davis T, Dipko S, Sigman R. Health Information National Trends Survey (HINTS) 2007 Final Report. Rockville, MD: Westat; 2009

26. Nelson DE, Kreps GL, Hesse BW, et al. The Health Information National Trends Survey (HINTS): development, design, and dissemination. J Health Commun. 2004;9:443-60.

27. Rutten LF, Moser RP, Beckjord EB, Hesse BW, Croyle RT. Cancer Communication: Health Information National Trends Survey. Washington, DC.: National Cancer Institute; 2007.

28. Glaser BG, Strauss AL. The discovery of grounded theory: strategies for qualitative research. Transaction Publishers; 2009

29. Thomas DR. A general inductive approach for analyzing qualitative evaluation data. Am J Eval. 2006;27:237-46.

30. Sweeny K. Crisis decision theory: decisions in the face of negative events. Psychol Bull. 2008;134:61-76.

31. Rittenhouse DR, Shortell SM. The patient-centered medical home: Will it stand the test of health reform? JAMA. 2009;301:2038-40.

32. Moore PJ, Sickel AE, Malat J, Williams D, Jackson J, Adler NE. Psychosocial factors in medical and psychological treatment avoidance: the role of the doctorpatient relationship. J Health Psychol. 2004;9:421-33.

33. Andersen RM. Revisiting the behavioral model and access to medical care: does it matter? J Health Soc Behav. 1995;36:1-10.
34. Iskandarsyah A, de Klerk C, Suardi DR, Soemitro MP, Sadarjoen SS, Passchier J. Psychosocial and cultural reasons for delay in seeking help and nonadherence to treatment in Indonesian women with breast cancer: a qualitative study. Health Psychol. 2014;33:214-21.

35. Ramirez AJ, Westcombe AM, Burgess CC, Sutton S, Littlejohns $\mathbf{P}$, Richards MA. Factors predicting delayed presentation of symptomatic breast cancer: a systematic review. Lancet. 1999;353:1127-31.

36. Scott SE, Walter FM, Webster A, Sutton S, Emery J. The model of pathways to treatment: conceptualization and integration with existing theory. Br J Health Psychol. 2013; 18:45-65.

37. Walter F, Webster A, Scott S, Emery J. The Andersen Model of Total Patient Delay: a systematic review of its application in cancer diagnosis. J Health Serv Res Policy. 2012;17:110-8.

38. Meyer D, Leventhal H, Gutmann M. Common-sense models of illness: the example of hypertension. Health Psychol. 1985;4:115-35.

39. Guide to Community Preventive Services. Increasing cancer screening: client reminders. http://www.thecommunityguide.org/cancer/screening/ client-oriented/reminders.html. (Accessed 5/21/14).

40. Kreps GL, Neuhauser L. New directions in eHealth communication: opportunities and challenges. Patient Educ Couns. 2010;78:329-36.

41. Chaudhry B, Wang J, Wu S, et al. Systematic review: impact of health information technology on quality, efficiency, and costs of medical care. Ann Intern Med. 2006; 144:742-52.

42. Blewett LA, Johnson PJ, Lee B, Scal PB. When a usual source of care and usual provider matter: adult prevention and screening services. J Gen Intern Med. 2008;23:1354-60.

43. Okoro CA, Strine TW, Young SL, Balluz LS, Mokdad AH. Access to health care among older adults and receipt of preventive services. Results from the Behavioral Risk Factor Surveillance System, 2002. Prev Med. 2005;40:337-343

44. Rezayatmand R, Pavlova M, Groot W. The impact of out-of-pocket payments on prevention and health-related lifestyle: a systematic literature review. Eur J Public Health. 2013;23:74-9.

45. Fennell ML, Das IP, Clauser S, Petrelli N, Salner A. The organization of multidisciplinary care teams: modeling internal and external influences on cancer care quality. JNCI Monographs. 2010;72-80.

46. Bynum SA, Davis JL, Green BL, Katz RV. Unwillingness to participate in colorectal cancer screening: examining fears, attitudes, and medical mistrust in an ethnically diverse sample of adults 50 years and older. Am J Health Promot. 2012;26:295-300.

47. Thompson HS, Valdimarsdottir HB, Winkel G, Jandorf L, Redd W. The Group-Based Medical Mistrust Scale: psychometric properties and association with breast cancer screening. Prev Med. 2004;38:209-18.

48. LaVeist TA, Isaac LA, Williams KP. Mistrust of health care organizations is associated with underutilization of health services. Health Serv Res. 2009;44:2093-105.

49. Hammond WP, Matthews D, Mohottige D, Agyemang A, Corbie-Smith G. Masculinity, medical mistrust, and preventive health services delays among community-dwelling African-American men. J Gen Intern Med. 2010;25:1300-8.

50. Arora NK. Interacting with cancer patients: the significance of physicians' communication behavior. Soc Sci Med. 2003;57:791-806.

51. Rao JK, Anderson LA, Inui TS, Frankel RM. Communication interventions make a difference in conversations between physicians and patients: a systematic review of the evidence. Med Care. 2007;45:340-9.

52. Penner LA, Gaertner S, Dovidio JF, et al. A social psychological approach to improving the outcomes of racially discordant medical interactions. J Gen Intern Med. 2013;28:1143-9.

53. Fawole OA, Dy SM, Wilson RF, et al. A systematic review of communication quality improvement interventions for patients with advanced and serious illness. J Gen Intern Med. 2013;28:570-7.

54. Anderson LA, Sharpe PA. Improving patient and provider communication: a synthesis and review of communication interventions. Patient Educ Couns. 1991;17:99-134.

55. Griffin SJ, Kinmonth AL, Veltman MW, Gillard S, Grant J, Stewart M. Effect on health-related outcomes of interventions to alter the interaction between patients and practitioners: a systematic review of trials. Ann Fam Med. 2004;2:595-608.

56. Clough J, Lee S, Chae DH. Barriers to health care among Asian immigrants in the United States: a traditional review. J Health Care Poor Underserved. 2013;24:384-403.

57. Nisbett RE, Wilson TD. Telling more than we can know: verbal reports on mental processes. Psychol Rev. 1977;84:231-59. 